Anuario Latinoamericano Ciencias Políticas

y Relaciones Internacionales

vol. 8, 2019

pp. $137-153$

\section{Alcances y desarrollo del movimiento feminista y el movimiento obrero en la conformación de una democracia social en el Perú oligárquico, 1887-1919}

\author{
The Feminist and Labor Movements and Their Quest \\ for a Social Democracy in Peru During the Oligarchical \\ Regime, 1887-1919
}

\author{
Juan Francisco Morales Giraldo* \\ FACULTAD DE DERECHO Y CIENCIA POLÍTICA \\ UNIVERSIDAD NACIONAL MAYOR DE SAN MARCOS \\ $\triangle$ jfmoralesg.88@gmail.com \\ https://orcid.org/0000-0002-7804-173X
}

\section{RESUMEN}

Entre 1887 y 1919 la sociedad peruana experimentó transformaciones asociadas a una temprana expansión capitalista y un proceso de modernización incipiente. La industrialización urbana, el alfabetismo y la emergencia de una nueva clase obrera fueron características de este periodo. Surgieron entonces movimientos sociales de carácter reivindicativo por el reconocimiento de derechos y libertades. El objetivo del estudio es analizar mediante un recuento histórico la importancia que tuvieron el movimiento obrero y el movimiento feminista en la conformación de una democracia social durante este periodo y las perspectivas de cambio del régimen oligárquico.

PALABRAS CLAVE: movimiento obrero, movimiento feminista, modernización, régimen oligárquico.

\section{ABSTRACT}

In a period from 1887 to 1919 Peruvian society experienced significant changes associated to early capitalist expansion and the basic stages of a modernization process. Urban industries, literacy and the emergence of a labor class were among

* Politólogo por la Pontificia Universidad Católica del Perú, con estudios complementarios en Relaciones Internacionales en la Academia Diplomática del Perú. Actualmente se desempeña como profesor en la Facultad de Derecho y Ciencia Política de la Universidad Nacional Mayor de San Marcos. Sus temas de interés son teoría de las relaciones internacionales, integración política, análisis estructural y dinámicas de competencia política.
DOI: 10.17951/al.2019.8.137-153 
Dossier América Latina: género y política the main aspects of this period, during which new social movements emerged to vindicate the recognition of social, political and civil rights and liberties. The purpose of this paper is to evaluate the importance of two particular movements -the labor movement and the feminist one- in the establishing of a social democracy and the perspectives of political change of the oligarchical regime.

KEYWORDS: labor movement, feminist movement, modernization, oligarchical regime.

\section{Introducción}

Entre 1887 y 1919 un proceso de modernización incipiente propició en el Perú la emergencia de nuevos movimientos sociales de carácter reivindicativo que tendrían un efecto transformador en los espacios económico, político y social. Provenientes de sectores sociales emergentes, los nuevos actores colectivos compartían una misma convicción de que la apertura de la esfera pública por medio de la movilización sería una estrategia viable para el cambio social y político, adoptando con ello una actitud crítica frente a un sistema inflexible en su mayor parte. Las movilizaciones consiguieron, entonces, inaugurar una nueva forma de hacer política en el país: la política de masas. ¿Cuál fue el alcance democratizador de estos movimientos? Dos décadas después, el régimen político y la sociedad en conjunto seguían siendo, en lo esencial, partes de un sistema excluyente. Pero, aunque las movilizaciones sociales no lograron avanzar en una mayor democratización política, sí lograron establecer ciertos principios básicos para una democracia social.

El presente trabajo plantea tres hipótesis sobre esta problemática como parte de un análisis que establece paralelos entre el movimiento feminista y el movimiento obrero entre 1887 y 1919. En primer lugar, las condiciones socioeconómicas en las que se originaron estos movimientos, que describen un periodo de modernización incipiente, tuvieron un alcance muy limitado, predominantemente urbano. En segundo lugar, aunque los movimientos conformaran de manera individual expresiones de una acción colectiva organizada, no lograron articular cadenas equivalenciales como estrategia de contestación frente al sistema en conjunto. Su actividad organizada fue básicamente sectorial. En tercer lugar, y en estrecha relación con los otros dos factores, la correlación de fuerzas política fue siempre favorable a la oligarquía que sostenía el régimen. Los movimientos sociales, al ser predominantemente urbanos, no lograron socavar las bases de poder de la clase dominante agrícola o de la emergente clase capitalista industrial. En ese sentido, fueron incapaces de alterar la capacidad de estas élites para recurrir a los instrumentos del aparato estatal -principalmente la fuerza armada- para mantener el statu quo en coyunturas críticas.

Tanto en el caso del movimiento feminista como del movimiento obrero, cada hipótesis encierra una suerte de dualidad visible en el desarrollo de 
ambos grupos. Primero, las características del contexto socioeconómico de la modernización incipiente durante este periodo sirvieron como condiciones causales en el origen de ambos movimientos, pero también como condiciones limitantes debido a las restricciones de su alcance urbano. Segundo, en ambos casos se alcanzó un nivel de organización favorable para una participación política efectiva, acorde con las bases ideológicas del anarquismo y el sindicalismo en que se inspiraron. Sin embargo, la participación política también estuvo limitada por la falta de articulación entre las diferentes demandas. Finalmente, lograron un poder relativo que aseguró concesiones en ciertas reivindicaciones importantes, pero no alteraron significativamente la correlación de fuerzas entre la élite y los grupos movilizados. En resumen, en cada condición actuaron fuerzas facilitadoras y limitantes que incidieron en el alcance transformador de ambos movimientos.

El contexto socioeconómico: industria y urbanización en una modernización incipiente

Los nuevos movimientos sociales surgen en las principales ciudades del país, especialmente en Lima, en un contexto de crecimiento de la industria manufacturera entre las décadas de 1880 y 1910. La expansión de la economía nacional durante la segunda mitad de la década de 1890 da lugar a una mayor diversificación de los sectores productivos con una base esencialmente local, inaugurando una etapa de desarrollo autónomo con un efecto transformador en la configuración demográfica de las clases urbanas. Es el periodo en el que emerge una clase obrera incipiente pero políticamente significativa.

La pérdida de interés de los capitales británicos (con una presencia predominante entre 1869 y 1900) en los proyectos de inversión peruanos derivó en un panorama económico poco alentador en los años posteriores al periodo de 1890-1892. La Crisis Baring (1890), la disminución del precio de la plata, larecesión comercial, el debilitamiento de la coalición de gobierno, las reticencias del Congreso a la aprobación del Contrato Grace (1888-1889), y las diferencias entre el propio gobierno y la Peruvian Corporation (creada por los tenedores de bonos en 1890) afectaron negativamente las buenas relaciones que se habían establecido con los capitales británicos. Desde 1892, entonces, la expansión económica debió organizarse, financiarse y controlarse localmente, hasta el posterior ingreso y consolidación de los capitales norteamericanos entre las décadas de 1910 y 1920 (Thorpy, Bertram, 1985, p. 31; Arequipeño y Jiménez, 1994)1․

1 La expansión industrial urbana en este periodo puede apreciarse a través de dos indicadores medidos entre 1891 y 1908. Primero, la disminución de importaciones de bienes de consumo en el monto total de importaciones. Los textiles, el sector manufacturero más importante, muestran una caída significativa en la proporción de importaciones: 29 \% en 1891-1892, $29,5 \%$ en 1897, 25,2 \% en 1900, $22 \%$ en 1902, y 14,7 \% en 1907 (Thorpy, Bertram, 1985, p. 45). Segundo, las cifras de producción local de textiles de algodón como porcentaje de la oferta total, comparadas con las cifras de importación del mismo tipo de productos. En 1891, la producción local ocupaba el $5 \%$ de la oferta total (1,5 yardas de 30). El $20 \%$ en 1898, $40 \%$ en 1902, $44 \%$ en 1905, y 47 \% en 1908 (Thorpy, Bertram, 1985, p. 46).

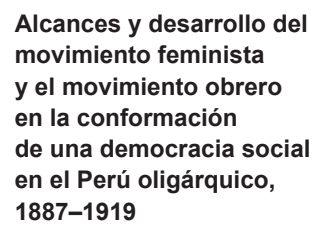

Juan Francisco Morales Giraldo 
Dossier América Latina: género y política

Tabla 1.

Industrias urbanas

hasta 1902
La expansión de nuevos sectores manufactureros en áreas urbanas, especialmente en la capital, sentó las bases materiales para el rápido crecimiento de una clase obrera que pronto comenzaría a movilizarse y organizarse políticamente en la reivindicación de demandas laborales. Este proceso puede observarse en el crecimiento del número de empresas o firmas establecidas en este sector desde la década de 1890 hasta principios del 1900 (Tabla 1). Desde 1890 hasta 1905, el número de empresas instaladas en áreas urbanas fue de más del 69 \% del total nacional. En el sector textil, donde el capital nacional conservaba gran participación y continuaba siendo preponderante (Garland, 1905, p. 115), sólo se habían instalado dos fábricas en Lima hasta comienzos de la década de 1890: la fábrica de tejidos de Vitarte (Peruvian Cotton M. C. "Vitarte") en 1890, y Santa Catalina, abierta en 1889. Luego se instalarían dos nuevas fábricas en 1897 y otras más en 1898 (La Victoria), 1901 (El Progreso) y 1903 (El Inca) ${ }^{2}$, todas concentradas en la capital, un área urbana de poco tamaño hasta entonces.

\begin{tabular}{|c|c|}
\hline Fecha de establecimiento & Número de firmas urbanas \\
\hline Antes de 1879 & 22 \\
\hline Década de 1880 & 12 \\
\hline $1890-1895$ & 42 \\
\hline $1896-1899$ & $21^{\mathrm{a}}$ \\
\hline $1900-1902$ & 11 \\
\hline Porcentaje de firmas urbanas instaladas desde 1890 & $60 \%^{\mathrm{b}}\left(69 \%^{\mathrm{c}}\right.$ hasta 1905$)$ \\
\hline Total de firmas industriales de carácter urbano & 149 (173 hasta 1905) \\
\hline \multicolumn{2}{|c|}{$\begin{array}{l}\text { a Cifra aproximada. El número real tiende a ser mayor. } \\
\text { b c Porcentajes aproximados. } \\
\text { Adaptado de R. Thorp y G. Bertram, 1985, Perú: 1890-1977. Crecimiento y políticas } \\
\text { en una economía abierta, Universidad del Pacífico, Lima; y A. Garland, 1905, Reseña } \\
\text { Industrial del Perú 1905, Ministerio de Fomento, Imprenta La Industria, Lima. }\end{array}$} \\
\hline
\end{tabular}

2 Las otras fábricas de tejidos existentes en 1905 en Lima, reconocidas en el censo industrial de ese año, pero de las cuales no se señalan las fechas de establecimiento en las fuentes revisadas, fueron: San Jacinto (60 telares), la de Andrés Malesta (80 telares), y la de Forga e Hijos (225 telares). Las fábricas Vitarte y El Inca contaban con 300 telares, La Victoria con 250 telares y El Progreso con 140. La Fábrica Nacional de Tejidos de Santa Catalina contaba con 70 telares en su apertura. Además de esta última, fuera de Lima funcionaban otras tres firmas que utilizaban la lana como materia prima: la fábrica de la hacienda de Urcon, abierta en 1861 en Pallasca (Áncash); la fábrica de tejidos de Lucre, abierta ese mismo año, y la fábrica de Marangani, instalada alrededor de 1905 en la provincia de Canchis (Cusco) (sobre esta información, véase Garland 1905, pp. 117-119). ¿Qué puede decirse acerca del impacto de estas fábricas en la conformación de un movimiento obrero de alcance nacional? No mucho. En la firma de Marangani, de 100 operarios e instalaciones modernas, los trabajadores eran exclusivamente indígenas, un hecho a considerar. El principal problema, sin embargo, es que muchas de estas fábricas eran las únicas en amplias regiones del país, sobre todo rurales, alejadas de otros centros industriales, lo que habría hecho difícil, si no imposible, el surgimiento de una masa obrera significativa, como sí ocurrió en las ciudades. 
La progresiva urbanización de la sociedad peruana fue otro aspecto vinculado a los cambios socioeconómicos de una modernización incipiente. Aunque la información desagregada sobre el crecimiento urbano entre 1890 y 1919, periodo que corresponde a este trabajo, es escasa, es posible hacerse una idea sobre el crecimiento poblacional urbano para el momento en que la nueva política de masas comenzaba a cobrar fuerza. Entre los años 1876 y 1940 en los que se realizaron censos, el conjunto urbano de Lima-Callao pasó de 129 mil a 595 mil habitantes, un crecimiento de 4,6 veces. En el resto del país el crecimiento poblacional sólo creció 2,3 veces en el mismo periodo (Hunt, 1980, p. 85, p. 105; Contreras, 2004, p. 181). Décadas más tarde, hacia 1940, la proporción de la población urbana en el país sería de 23,6 \%.

\begin{tabular}{lccc}
\hline $\begin{array}{l}\text { Sector económico } \\
\text { de carácter urbano }\end{array}$ & $\begin{array}{c}\text { Número de empleos } \\
\text { en } 1876\end{array}$ & $\begin{array}{c}\text { Número de empleos } \\
\text { en 1908 }\end{array}$ & $\begin{array}{c}\text { Crecimiento sectorial } \\
\text { del empleo (1876-1908) }\end{array}$ \\
\hline Industria & 6,783 & 19,191 & $182.9 \%$ \\
\hline Construcción & 3,176 & 6,732 & $112 \%$ \\
\hline Transporte & 1,160 & 1,827 & $57.5 \%$ \\
\hline Comunicación & 35 & 166 & $374.2 \%$ \\
\hline Comercio & 4,191 & 7,795 & $85.9 \%$ \\
\hline Servicios & 14,522 & 22,184 & $52.7 \%$ \\
\hline Gobierno & 4,331 & 8,681 & $100.4 \%$ \\
\hline Población total & 120,994 & 172,927 & $42.9 \%$ \\
\hline
\end{tabular}

Adaptado de "Evolución de los salarios reales en Perú 1900-1940", por S. Hunt, 1980, Economía, vol. 3, no. 5, pp. 83-123.

Hacia 1908, el empleo en los sectores económicos de carácter urbano había crecido considerablemente en la provincia de Lima, ocupando el $11 \%$ del total (Tabla 2). Junto con la expansión urbana aparece una nueva industria de bienes de consumo y crece el sector de servicios, que en poco tiempo desplazan a las antiguas manufacturas artesanales (Contreras, 1994, p. 10) ${ }^{3}$. En cuanto a vivienda, aparecieron en Lima los barrios obreros de La Victoria, Breña y Lince, que se sumaban al naciente distrito de Vitarte cuando entre 1907 y 1910 comenzaron a construirse viviendas alrededor de la fábrica textil (sobre el fenómeno de este centro poblado, y la estrategia paternalista de la gerencia textil para incentivar su formación, véase Sanborn, 2004, pp. 193-200). Otros sectores sociales también crecieron en medio de estos cambios socioeconómicos. Según datos del Censo General de 1876 y el Censo de la Provincia de Lima

3 El número de empresas de fabricación de bienes de consumo se incrementó en un 70 \% en el corto periodo de 1890 a 1902. La participación de los bienes de consumo en las importaciones totales cayó de 58 \% en 1890-1892 a 49 \% en 1900 y 39 \% en 1907 (Klaren, 2004, p. 257). Durante este primer desarrollo industrial se creó la Sociedad Nacional de Industrias.
Alcances y desarrollo del movimiento feminista y el movimiento obrero en la conformación de una democracia social en el Perú oligárquico, 1887-1919

Juan Francisco Morales Giraldo

Tabla 2. Porcentaje de crecimiento del empleo en sectores económicos urbanos en la provincia de Lima, 1876-1908 
Dossier América Latina: género y política de 1908, en la capital el número de empleados asalariados entre esos años pasó de 950 a 6821, el de tenderos creció de 845 a 1382 y el número de periodistas se multiplicó por casi diez veces (un indicador de la creciente importancia de la prensa escrita en la vida social).

El crecimiento de la escolaridad y del alfabetismo, sobre todo en ciudades, y especialmente en la capital, fue otro aspecto característico de esta modernización incipiente. Los movimientos sociales en este periodo emplearon los medios escritos como instrumentos de organización y propaganda, de modo que la prensa escrita cumplió un papel crucial convirtiéndose en una tribuna política para los sectores sociales desplazados de las esferas del poder desde los tiempos de la Reconstrucción y el Segundo Militarismo (1883-1895) (McEvoy, p. 1997). La fundación del diario La Prensa en 1903, y su fusión con el diario El Tiempo en 1905, fue el comienzo de ese proceso expansivo del debate público, constituyendo ambos "los pasos iniciales en la forja de un [nuevo] espacio político capaz de confrontar mediante la discusión pública el comportamiento y la legitimidad..." del Civilismo (McEvoy, 1997, p. 393). La prensa escrita no era un fenómeno nuevo en la política peruana, pero a diferencia de lo que había significado en el siglo pasado, su actual importancia obedecía a una expansión de la propia opinión pública, lo que a su vez respondía a un incremento en las cifras de escolaridad y alfabetismo entre los sectores urbanos, anticipando una eclosión de la palabra escrita entre 1904 y 1919 (McEvoy, 1997).

En 1876, el $9 \%$ de la población de Lima estaba dedicada a alguna tarea educativa, pero en 1908 ese porcentaje se había elevado al $18 \%$. Entre 1906 y 1907, el número de alumnos matriculados en las escuelas primarias del país creció alrededor del $5 \%$, mientras que el número de analfabetos disminuyó en un 26,3\%. Por lo menos en Lima, el porcentaje de escolaridad infantil alcanzó el 70 \% (McEvoy, 1997, pp. 396-397; ver también Basadre, 2005 [1939], tomo 16$, p. 88$)^{4}$. El crecimiento anual del gasto estatal para la instrucción pública durante la reforma educativa del gobierno de José Pardo (1905) -9,63\% del gasto público en $1904,10,22 \%$ en $1905,15,85 \%$ en $1906,17,24 \%$ en 1907 , y $16,14 \%$ en 1908 (Martín, 1996, p. 418; Basadre, 2005 [1939], tomo 16, p. 114)- da una idea del impacto que tendrían los efectos de esta política educativa en la conciencia de la sociedad civil durante las mayores movilizaciones sociales en la década siguiente. Vista en perspectiva, la reforma educativa de 1905 del presi-

4 "Los cambios en la demografía de la ciudad fueron de la mano con una mejora notable en los niveles de alfabetización urbana [...] La ley, que bajo el número 162, fue promulgada el 5 de diciembre de 1905, señaló en su artículo primero la obligatoriedad de la instrucción primera elemental. La misma se suministraría gratuitamente, junto a los libros y útiles de enseñanza, a los varones de seis a catorce años, y a las mujeres de seis a doce. Por resolución del 14 de febrero de 1906 el gobierno adquirió muebles y útiles de enseñanza para las escuelas fiscales [o nacionales]. Las cantidades mencionadas en la resolución gubernativa, que también contempló la creación del 'Consejo Nacional de Educación' [en junio de 1907], pueden dar cuenta de la magnitud de la reforma educativa en la que el gobierno de José Pardo se embarcó” (McEvoy, 1999, pp. 288-289). 
dente José Pardo ${ }^{5}$ fue la puesta en práctica de una concepción progresista de la educación que favoreció principalmente a la profesionalización de la clase media y la formación de una conciencia de clase en la emergente clase obrera mediante la difusión de la propaganda escrita.

Las condiciones descritas dan cuenta de un proceso de transformaciones en el que las castas heredadas de la antigua sociedad colonial son progresivamente reemplazadas por un sistema de clases capitalista. En ese sentido, la ciudadanía que parte del reconocimiento de derechos que demandan los nuevos movimientos coincide con este surgimiento de un capitalismo temprano, que es, como sostenía Marshall (1997), un sistema de desigualdad. Las dinámicas de estos movimientos, sus alcances y su interacción con los grupos de poder, pueden ayudar a explicar cómo es que ambos principios, ciudadanía y desigualdad de clases, pudieron coexistir, y hasta qué punto.

\section{Las dinámicas del movimiento obrero y el movimiento feminista}

Las transformaciones sociales producidas por este proceso de modernización condujeron a un despliegue de reivindicaciones y demandas que se plasmaron en el surgimiento de cuatro importantes movimientos sociales: obrero, feminista, estudiantil e indigenista. Dos de ellos en particular, el movimiento obrero y el movimiento feminista, aportaron nuevas exigencias en materia de derechos sociales, civiles y políticos con metas alternativas de emancipación -en el caso particular del movimiento feminista- y organización social (cf. Pérez, 2012). La dinámica de ambos estará influenciada por dos ideologías sobre las cuales se construirá la cultura política del país: el anarquismo en una primera etapa, y fundamentalmente el socialismo. Este último será la doctrina

5 La posición del presidente Pardo en el debate que mantuviera con Alejandro Deustua demuestra, en sus propias palabras, el alcance de sus ideas y el carácter de los principios sobre los que basaba su política educativa. "En medio de la unanimidad con que se juzgaba la política escolar del Gobierno se produjo una nota discordante", reclamó el presidente. "El doctor Deustua, profesor en la Facultad de Letras [...], circuló un folleto en que criticaba esta dirección, sosteniendo que la primera necesidad nacional en orden a la educación era la formación de la 'elite' que ha de tener más tarde la dirección de las ideas y del Gobierno mismo del país. Este folleto circuló en los días de la clausura de la Universidad y como, dado el autor y dada la ceremonia que iba a tener lugar, yo no podía dejar de contestar [...] En los periódicos se publicaron mis palabras, respuesta al discurso del Rector [...] Sostuve que la educación debe de ser democrática. Y esta es la verdad. No hay duda que, en todo régimen de país de cierta cultura [...] el Gobierno del país corresponde a la 'elite' de sus hijos, pero no hay país en el mundo ni los de organización aristocrática más severa, que tenga el régimen de educación organizado para formar esa 'elite'; escuelas, colegios y universidades, están al alcance de pobres y de ricos, de patricios y plebeyos, de inteligentes y de torpes. Este es el deber del Estado. Educación para todos. La 'elite' se forma sólo por la superioridad de inteligencia y de cultura." (José Pardo, "Lo que mis hijos deben conocer”, Instrucción 1904, Memorias inéditas, Archivo Pardo; citado en Martín, 199, pp. 422-423).
Alcances y desarrollo del movimiento feminista y el movimiento obrero en la conformación de una democracia social en el Perú oligárquico, 1887-1919

Juan Francisco Morales Giraldo 
Dossier América Latina: género y política que permitirá la posterior evolución de la movilización social como principal estrategia reivindicativa, a la organización centralizada de partidos políticos de masas hacia la década de 1920.

El movimiento obrero comienza a organizarse tempranamente durante los primeros años de la expansión del capitalismo en el periodo de reconstrucción nacional. En 1886, se funda la Confederación de Artesanos Unión Universal, una organización de corte reformista predominante durante la etapa temprana del movimiento obrero. Al año siguiente, en 1887, se funda la Sociedad de Obreros Panaderos Estrella del Perú -renombrada luego en 1904 como una federación- que llevaría a cabo una huelga ese mismo año. También en 1887 se fundó la Asamblea de Sociedades Unida; y más tarde, la de trabajadores textiles, que en agosto 1896 organizarían la primera huelga general obrera, una movilización de solidaridad que será el primer ejemplo de articulación de demandas particulares en el seno de la clase trabajadora, con la participación de los cigarreros (septiembre), tipógrafos ${ }^{6}$ (también en septiembre) y panaderos de la capital. La Federación de Obreros Panaderos Estrella del Perú, de corte anarquista, sería una de las más importantes de la década de 1900, arrebatando el predominio a la reformista Unión Universal. Serían, además, los primeros en conmemorar en 1905 el 1 de mayo como día del trabajador. El resultado de la pugna entre reformistas y anarquistas al interior del movimiento obrero sería decisivo. En el Primer Congreso Nacional Obrero celebrado en 1901 ya se habían hecho públicas las reclamaciones de la clase trabajadora (reducción de las jornadas laborales, salario justo, abaratamiento de subsistencias, etc.), pero también se había hecho evidente el radicalismo anarquista que estaba tomando forma en los núcleos obreros de Lima y otras ciudades. La corriente anarquista privilegiaba la acción directa como modo de contestación política. Esta tendencia es la que eventualmente definirá la movilización política del sector obrero hacia mediados de la década de 1910, cuando consigan el mayor de sus triunfos.

Ya en 1904 los panaderos y obreros portuarios habían organizado una huelga de solidaridad por la jornada laboral de 8 horas. Volvieron a hacerlo en 1911, pero esta vez como un paro nacional en apoyo a los tejedores de Vitarte. El resultado fue la supresión del trabajo nocturno. Ese mismo año, finalmente, el movimiento trabajador consigue la promulgación de la ley de accidentes de trabajo durante el primer gobierno de Augusto B. Leguía. Pero el mayor evento que involucró al movimiento obrero en este periodo es quizás las Jornadas Cívicas de 1912 que llevaron a la presidencia a Guillermo Billinghurst, las primeras elecciones de características extrapartidarias y de carácter verdaderamente popular. Parte de estas movilizaciones fueron las huelgas por las ocho horas que se sucedieron e intensificaron entre 1912 y 1913, y con lo cual la Unión de Jornaleros del Callao conquistaría las 8 ocho horas en 1913.

6 El primer caso de acción reivindicativa que utiliza la huelga como medio de presión lo constituye el paro de los tipógrafos por mejoras salariales en diciembre de 1883 (Delhom, 2001). 
Finalmente, durante la huelga general de 1918-1919 en el segundo gobierno de José Pardo, el movimiento obrero lograría, por fin, la aprobación de la Ley General de las 8 horas de trabajo.

Por otra parte, el movimiento feminista en su primera etapa surge y cobra fuerza en la década de 1910 con una actividad que se prolongará hasta 1924, coincidiendo con el proceso de modernización social y económica de la sociedad peruana, especialmente en Lima, "un espacio de cambios materiales y nuevas ideas" (Zegarra, 2011, p. 38). Este lapso temporal abarca también la primera etapa del activismo de María Jesús Alvarado (Chincha Baja 1878 - Lima 1971) como precursora y una de las figuras más importantes de este movimiento. Su actividad pública comienza en 1908 como redactora de los diarios El Comercio y La Prensa, pero es a partir de 1911 que sería reconocida como representante de la lucha reivindicativa de la mujer en el país. En octubre de ese año ofreció una conferencia titulada El feminismo en el auditorio de la Sociedad Geográfica de Lima que marca el comienzo de la primera etapa del feminismo en el Perú. En él, abogaría explícitamente por una defensa más activa de la igualdad de derechos civiles y políticos entre mujeres y hombres. En 1914, fundaría junto a Adela Montesinos, otra destacada activista feminista, la organización Evolución Femenina, y en 1915 la Escuela-Taller Moral y Trabajo para dar educación laboral a hijas de obreros. Pronto, el alcance del movimiento femenino desbordó los márgenes de la capital. En 1918, se fundaría en Huacho el Centro de Estudios Femeninos Luz y Libertad. En ese contexto de movilización y creciente organización política, se fundaría el Consejo Nacional de Mujeres, en 1923, como órgano representativo de las asociaciones femeninas de todo el país. Finalmente, en 1924, se organizaría en el Perú la Segunda Conferencia Panamericana de Mujeres.

Un elemento importante en las reivindicaciones de este movimiento fue la reforma de la educación general, y sobre todo de la educación de la mujer. "Al plantearse el trascendental problema de la instrucción media y superior de la mujer", reclamaba María Jesús Alvarado, "hay que tener en cuenta la triple faz doméstica, sociológica y económica que presenta" (Educación femenina, 1911, citado en Chaney, 1988, p. 60). Sobre el aspecto económico de la educación femenina, quedaba claro en sus palabras que éste resultaba ya una necesidad fundamental dada la situación de la mujer en una sociedad moderna:

No todas las mujeres tienen bienes de fortuna para vivir en la molicie, o encuentran un esposo que provea a las más apremiantes necesidades de su vida; una inmensa mayoría hay de solteras, viudas y aún de casadas, con hombres ineptos o disolutos, que carecen absolutamente de recursos, no teniendo en general más medio para proporcionárselos que la costura exiguamente remunerada, porque la deficiencia de su educación y seculares prejuicios sociales la imposibilitan para dedicarse a más fructuosas labores. Estas circunstancias premiosas, en que muchas veces naufraga el honor de las familias, es la que ha arrancado a la mujer de su forzada inercia y de-
Alcances y desarrollo del movimiento feminista y el movimiento obrero en la conformación de una democracia social en el Perú oligárquico, 1887-1919

Juan Francisco Morales Giraldo 
Dossier América Latina: género y política presiva ignorancia, emprendiendo esa intrépida campaña de reivindicación que se llama "feminismo" y que tan grandes triunfos cuenta ya en el mundo civilizado [...] en vista de que la aguda crisis económica en la que la vida moderna coloca a la mujer hace preciso dotarla de una elevada instrucción que le sirva para emprender honrada y ventajosamente la lucha por la existencia... (María Jesús Alvarado, "Instrucción media y superior para la mujer”, Educación femenina, en Chaney, 1988, p. 61)

¿Cuál era la situación laboral de la mujer y por qué resultaba imperioso mejorarla reconociendo su igualdad moral e intelectual? El caso del sector industrial textil resulta un ejemplo aleccionador, al menos en parte, y establece algunos matices y puntos en común con el movimiento obrero. Entre los años 1900 y 1930, las mujeres representaban entre el $25 \%$ y el $30 \%$ de la población económicamente activa de Lima, pero concentraban los menores ingresos y trabajaban en peores condiciones laborales. En 1912, eran el $20 \%$ de los trabajadores de la fábrica textil de Vitarte, uno de los principales centros industriales de la capital; en 1918 ya constituían el 40 \% (Sanborn, 2004, p. 192). En la fábrica como espacio social ${ }^{7}$, y en general en el mercado laboral, la situación de la mujer no era sencilla. Eran conscientes de que, a pesar de las duras condiciones laborales, del salario bajo, del chantaje sexual y de los despidos arbitrarios por embarazo, la fábrica les daba mayores oportunidades que otros sectores laborales tradicionalmente femeninos, como la cocina, el lavado y el trabajo doméstico. Pero a decir de Sanborn (2004, p. 203), dadas las condiciones de extrema pobreza de las mujeres de clase obrera, y las propias condiciones de desigualdad de la sociedad de la época en general, la identidad familiar y obrera de estas mujeres predominaba sobre su identidad de género. Pese a esto, las reivindicaciones feministas eran relevantes para mujeres de diversa condición y origen socioeconómico. Para las mujeres de clase media y alta, el trabajo fuera del hogar resultaba deshonroso. "Excluidas en virtud de su delicadeza y menor inteligencia mundana -mas no espiritual- de las actividades políticas e intelectuales, la única posibilidad que se les concedía [a las mujeres] era 'entretenerse' en labores femeninas: bordar, hacer encajes, arreglar flores, tocar el piano, rezar y 'administrar' la casa...” (Francke, 1990, p. 96; ver también Zegarra, 2011, p. 38-41). Para las mujeres de sectores populares, en cambio, el trabajo intensivo -como el de una fábrica textil- era parte de sus vidas desde temprana edad. Sin embargo, en ambos casos, la educación y el reconocimiento de derechos civiles, políticos y sociales apuntaban a objetivos comunes propios de su situación de género: para unas, resultaba una manera

7 Un espacio social "es el producto de las interacciones y complejidades, los entrecruzamientos y las desconexiones, de las relaciones, desde lo inmenso de lo global hasta lo ínfimo de la intimidad" (Massey, 2005, pp. 156-157, 173). En ese sentido, se constituyen por medio de una multiplicidad de interacciones y posibilidades. Para la mujer de clase obrera, la fábrica configuraba un espacio en el que se constituían, de manera exclusiva o complementaria, una conciencia de clase y una identidad de género. 
de insertarse en el mercado laboral, para otras, una manera de mejorar su condición laboral, aspirar a mejores salarios y asumir otras funciones hasta entonces restringidas a los hombres. Para ambas, era un reconocimiento a su condición de ciudadanas plenas. "El principio fundamental del feminismo diría Alvarado en su más famosa contribución al movimiento- es la igualdad de la potencialidad mental y de la habilidad para el trabajo del hombre y de la mujer..." (El feminismo, 1911). En medio de las transformaciones que caracterizaron este periodo, se dieron las condiciones para una progresiva inserción de la mujer en la economía, así como para la participación política, sea al interior del propio movimiento feminista o como parte del movimiento obrero, sean motivadas por una conciencia de género o una conciencia de clase.

En conclusión, en este breve recuento de hechos se ha podido constatar que tanto el movimiento obrero como el movimiento feminista estuvieron vinculados, en sus orígenes, a un cambio general en las condiciones socioeconómicas, al crecimiento de las industrias urbanas y a una creciente importancia de la ciudad en la vida social. El desarrollo de ambos movimientos siguió la misma tendencia expansiva del propio capitalismo temprano, con la particularidad de que los cambios socioeconómicos en marcha, la modernización y la movilización social fueron fenómenos urbanos con un alcance muy limitado.

\section{Los alcances de la movilización social: más derechos sin democracia}

Los cambios socioeconómicos de este periodo favorecieron avances hacia democracia de corte liberal en la medida en que permitieron que nuevos sectores sociales actuaran políticamente a favor del reconocimiento de derechos sociales, civiles y políticos. Su activismo abrió la esfera pública a la participación popular en momentos en que la economía nacional urbana avanzaba lentamente hacia un capitalismo en sus etapas iniciales, lo que respalda en alguna medida dos tesis clásicas sobre los requisitos sociales para la democracia: a) la tesis sobre el capitalismo como condición necesaria, aunque no suficiente, para la democratización de la sociedad; y b) la tesis de una sociedad civil fuerte como base política para la democracia (Lipset, 1996; Acemogluy, Robinson, 2006, p. 31). La idea de una ciudadanía organizada como requisito predemocrático hace énfasis en el rol de las organizaciones civiles como instituciones mediadoras y facilitadores de una voluntad popular. En el Perú de las décadas de 1900-1910, los partidos políticos eran más bien organizaciones de élite, diseñados para mediar entre facciones en un régimen político igualmente de élites. En cambio, la activación de los movimientos sociales sí trajo consigo la fundación de organizaciones civiles con propósitos reivindicatorios: federaciones, sindicatos y escuelas. Por eso no es difícil constatar que antes de la aparición de los partidos de masas en la década de 1920, las organizaciones obreras y feministas ya sirvieran como instituciones mediadoras frente a un Estado conservador.
Alcances y desarrollo del movimiento feminista y el movimiento obrero en la conformación de una democracia social en el Perú oligárquico, 1887-1919

Juan Francisco Morales Giraldo 
Dossier América Latina: género y política
Las organizaciones y la participación política fomentaron una democratización de tipo básicamente social que se extendió a espacios como la fábrica (cf. Bobbio, 2006b). Los sindicatos, federaciones y organizaciones feministas, de alguna forma vinculadas al movimiento obrero, sirvieron además para alimentar el doble proceso de participación y adquisición de una conciencia ciudadana (cf. Macpherson, 2009, pp. 120-121). Al generar una mayor conciencia sobre su situación social y política, la participación democrática se hizo posible. En resumen, apertura, participación y democracia social fueron el resultado de la acción de los nuevos movimientos sociales entre las décadas de 1900 y 1910.

Sin embargo, y a pesar de estos cambios, estas mismas condiciones socioeconómicas, favorables a la transformación social y política, se dieron de manera desigual en el resto del país, entre la ciudad y el campo. Mientras el movimiento obrero obtenía victorias en su lucha reivindicativa entre las décadas de 1910 y 1920, y crecía su afinidad con los nuevos partidos políticos, la ley de conscripción vial del presidente Augusto B. Leguía obligaba legalmente a la población campesina indígena a trabajar de manera gratuita en la construcción de caminos y carreteras, lo que en la práctica constituyó la reanudación de la mita colonial (Cotler, 2005, p. 182-183). Difícilmente los movimientos sociales en la ciudad podrían haber revertido la situación política y social del resto del país.

Por otra parte, las condiciones socioeconómicas características de este periodo permitieron reivindicar una inserción de la mujer como ciudadana con plenos derechos. Evidentemente, los talleres del siglo XIX no englobaban las mismas condiciones que la fábrica del siglo XX. El movimiento feminista organizado, políticamente activo y no sólo discursivo, fue un fenómeno intrínsecamente asociado al proceso de modernización y expansión capitalista. Si se piensa en la manera como el movimiento feminista fue cobrando forma puede afirmarse que existe un factor muy similar a lo ocurrido con el desarrollo del movimiento obrero: la organización civil. Como los obreros, las mujeres se organizaron en asociaciones. Lo que hizo la diferencia para el surgimiento del movimiento feminista fue la adopción del sindicalismo como estrategia, algo que ya había demostrado ser efectivo en el caso del movimiento obrero desde la década de 1880, para quienes la estrategia sindicalista fue mucho más exitosa en el contexto socioeconómico de las décadas de 1900-1910, con un nivel de organización mayor que el que permitía la doctrina anarquista. En resumen, el feminismo se hizo movimiento social cuando se sindicalizó. Detrás del movimiento feminista actuaron las mismas condiciones facilitadoras que en el movimiento obrero: condiciones socioeconómicas de apertura y movilización, y niveles relativamente elevados de organización. Pero ambos comparten también limitaciones: el movimiento feminista, como el obrero, fue predominantemente urbano. 


\section{Demandas democráticas y cadenas de equivalencias}

¿Cómo se articularon internamente los movimientos sociales en este periodo? La respuesta es a través de la comunicación escrita, y quizás donde la relación entre ésta y la movilización social sea más evidente, es en el campo del movimiento obrero. Algunas publicaciones de corte liberal y de crítica sociopolítica ya venían cumpliendo una destacada labor de educación y concientización de la clase trabajadora desde finales del siglo XIX. Ejemplos de estas primeras publicaciones son los diarios La Luz Eléctrica (1886-1897), Integridad (18891891), Germinal (1889; 1901-1906), El Libre Pensamiento (1896-1904) y La Idea Libre (1900-1920) (Delhom, 2001). En otra orilla ideológica, aparecieron órganos de clara orientación anarquista, la cual sería predominante en el movimiento trabajador de las primeras dos décadas del siglo XX. Estas publicaciones de tendencia anarquista fueron las que permitieron articular las ideas y las reivindicaciones del movimiento trabajador con una opinión pública que ya habían crecido gracias, entre otras cosas, a las mejoras educativas. El mensual Los Parias, que había empezado a circular en 1904, fue el primer medio anarquista del país. Hubo también otros medios de organización y propaganda. En Lima y otras ciudades, se fundaron centros intelectuales para el estudio y la discusión de la problemática obrera, y que articulaban su activismo con el de los obreros a través de medios escritos como diarios o revistas. Entre los brazos intelectuales de la militancia obrera se encontraban el Centro de Estudios Sociales Humanidad -fundado en 1906 con un diario del mismo nombre- y el Centro Socialista $1^{\circ}$ de Mayo -con su diario El Oprimido-, ambos fusionados en 1908 con el nombre de Centro de Estudios Sociales $1^{\circ}$ de Mayo. El Centro de Luchadores por la Verdad, de corte anarquista, también fue fundado alrededor de esos años, y editó desde 1911 hasta 1926 el que sería el principal diario anarquista del país en esa época: La Protesta. Otros diarios partes del movimiento trabajador y de tendencia anarquista fueron El Hambriento (1905-1910) y La Simiente Roja (1905-1907). Fuera de Lima se fundaron, entre otros, el Centro Social Obrero (1905), la Sociedad Patriótica de Artesanos y diarios como El Ariete en Arequipa; la Confederación de Obreros $1^{\circ}$ de Mayo en Chiclayo (1907); y en Trujillo se fundaron los centros de estudios sociales Luz e Hijos del Pueblo junto con diarios como La Antorcha y El Rebelde (Delhom, 2001).

Una manera de comprender cómo es que el movimiento obrero y el movimiento feminista surgen y se consolidan en parte gracias al papel jugado por la comunicación escrita, es remitiéndonos a la teoría de la representación de Laclau (2005). En primer lugar, a medida que el sector industrial

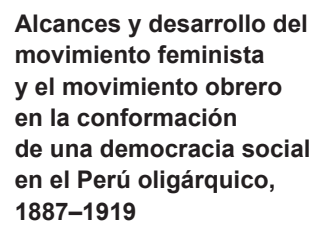

Juan Francisco Morales Giraldo

8 Otros diarios no vinculados a los movimientos sociales de la época, pero que formaron parte también de la eclosión del mercado de lectores de la época, son reseñados en Basadre (2005, tomo 16, pp. 172-176). 
Dossier América Latina: género y política

crecía en la década de 1900, crecían también las demandas democráticas ${ }^{9}$ de la clase obrera por derechos laborales; el problema era que el sistema político en algún punto fue incapaz de resolverlas de manera diferencial, es decir, de manera separada, ya sea por desidia o porque las demandas en sí no representaban un problema real para la clase industrial y sus aliados en el poder. Esto fue creando una cadena equivalencial entre los grupos demandantes, lo que explica que, por ejemplo, telegrafistas y panaderos se hayan movilizado primero de manera independiente en las décadas de 1880-1890, y que recién entre 1900-1910 hayan constituido frentes únicos, hasta los paros generales de 1896, 1911, las jornadas cívicas de 1912 y la huelga general de 1918-1919. Las demandas democráticas de cada sector de trabajadores se convirtieron en demandas populares de la clase obrera, y en este tránsito la comunicación escrita por medio de revistas, diarios y panfletos sirvió como instrumento de articulación, ayudando a generar los significantes que dieran soporte al papel de representación de los sindicatos y del movimiento que lideraban. Lo que habría que resaltar, finalmente, es que esta cadena de equivalencias, este proceso de construcción de una voluntad colectiva no integró de manera orgánica a otros movimientos.

\section{La resistencia del régimen conservador}

La conclusión de este recuento histórico sobre el desarrollo y los alcances transformadores de los movimientos obrero y feminista apunta, finalmente, a la resistencia de la élite política frente a las perspectivas de cambio social y político. ¿Cuál fue la reacción de la élite gobernante frente a las reivindicaciones de los nuevos movimientos sociales? Una combinación de apertura, concesiones, renuencia y represión. Desde la década de 1890, la ausencia de un aparato estatal sólido y de una política de participación abierta habían permitido a la plutocracia civilista extrapolar a la esfera pública las formas de organización familiar y privada que les caracterizaba (McEvoy, 1997, p. 391). La hegemonía conservadora del partido Civilista y sus aliados entre las décadas de 1890 y 1910 consolidó un régimen político cerrado con rasgos particulares, que puede describirse como una "república aristocrática" (Bobbio, 2006), una "oligarquía constitucional” (Rueschemeyer, Stephens, Stephens, 1992 $)^{10}$, o en general, un elitismo competitivo, en el que el poder, ejercido por un grupo social minoritario, residía en la concentración de recursos materiales y simbólicos. La movilización de grupos obreros y femi-

\footnotetext{
9 "Democráticas" en el sentido laclauniano. Véase Laclau (2005, cap. 4, apéndice).

10 "La diferencia entre la voluntad de un colegio restringido, como puede ser el de una república aristocrática”, dice Bobbio, "y la de una asamblea popular, como puede ser la de una república democrática, no es tan relevante como la diferencia entre la voluntad del soberano único (...) y la de un soberano colectivo (...); lo que cambia en el paso de la república aristocrática a la república democrática solamente es la diferente formación de la voluntad colectiva” (2006, p. 65).
} 
nistas, entre otros, planteaba una crítica directa a esta manera de abordar los asuntos públicos ${ }^{11}$.

La reacción de las élites conservadoras a la acción reivindicativa del movimiento obrero y el movimiento feminista fue similar. Durante las Jornadas Cívicas de 1912 -la protesta obrera más importante hasta entonces- la reacción de los grupos de poder fue la reactivación de un frente cívico-militar con el apoyo de algunos sectores medios, que en poco tiempo promovieron el golpe de Estado de 1914 del coronel Óscar R. Benavides para deponer al progresista Billinghurst. La élite intelectual de la capital se organizó en torno al Partido Nacional Democrático (1915), un movimiento de corte intelectual y cultural. Finalmente, la respuesta más firme de la élite política conservadora provino de la Convención de Partidos Políticos de 1915, una coalición entre los partidos Civilista, Liberal y Constitucional. De manera previsible, ninguna de las propuestas de la Convención, ni de los proponentes del Partido Nacional Democrático, estuvieron diseñadas para canalizar efectivamente las demandas de los nuevos movimientos reivindicativos. La convulsión social y política marcaría el segundo gobierno de José Pardo (1915-1919) hasta el surgimiento de un republicanismo conservador renovado: la Patria Nueva de Augusto B. Leguía.

Hacia finales de este periodo, el movimiento feminista fue diluyéndose y sus partidarias fueron absorbidas por los nuevos partidos políticos. ¿Qué significó el movimiento feminista para la sociedad peruana en esta primera etapa? La resistencia a la subordinación de género, como otras formas de resistencia y reivindicación a través de la acción social, fue un movimiento a contracorriente de una moral sexual de tintes coloniales que había cambiado poco desde entonces (sobre esto, ver Francke, 1990). El movimiento feminista fue un movimiento radical en algún sentido. Las propias palabras de María Jesús Alvarado reflejan bien la clase de ideas y actitudes a las que se enfrentaba con un discurso abiertamente confrontacional: denunciaba la subordinación de la mujer como la "tiranía del patriarcado", donde su situación pasa "de la esclavitud del padre [...] a la del esposo", donde "se mantiene su inteligencia en oscuridad y sólo se le ejercita en los quehaceres domésticos". De manera más explícita, aclararía luego: "el principio fundamental del feminismo es la igualdad de la potencialidad mental y de la habilidad para el trabajo del hombre y de la mujer.... El precio que pagó el movimiento feminista por su radicalidad fue alto. En 1923, María Jesús Alvarado y la organización Evolución Femenina ya habían remitido a la Comisión de Reforma del Código Civil de 1851 un petitorio para el reconocimiento de los derechos civiles y políticos de

11 Este régimen oligárquico compartía algunos rasgos de la democracia shumpeteriana: un método político por el cual líderes rivales competían por el mandato para gobernar, con un escaso universo de electores limitado únicamente a autorizar y otorgar una legitimidad formal menos importante que la legitimidad que emana de la posición social. Pero a diferencia de este modelo de democracia, entre la oligarquía peruana los líderes rivales representaban, a lo mucho, posiciones discrepantes al interior de la propia clase gobernante (Held, 2007, pp. 204, 211, 214).
Alcances y desarrollo del movimiento feminista y el movimiento obrero en la conformación de una democracia social en el Perú oligárquico, 1887-1919

Juan Francisco Morales Giraldo 
Dossier América Latina: género y política

las mujeres. Un proyecto de ley en ese sentido sería aprobado y promulgado recién en 1936, pero la ley del voto femenino sería promulgada mucho más tarde, en 1955.

\section{Conclusión}

Partiendo de una analogía con el argumento de Marshall (1997, p. 15) sobre la coexistencia entre derechos y capitalismo -igualdades vs. desigualdades-, durante la República Aristocrática la participación política y ciertas libertades civiles y sociales reconocidas en la vida pública, en la fábrica, o en el hogar, no consiguieron consolidar una democracia plena, pero sí un cierto grado mínimo de democracia social necesaria para el mantenimiento de un sistema político cuya legitimidad simbólica retrocedía cada vez más en favor de una legitimidad formal e instrumental. Condiciones socioeconómicas restringidas, una articulación organizativa débil entre asociaciones civiles, y un régimen sostenido por grupos de poder reaccionarios limitaron el impacto democratizador del movimiento y el movimiento feminista, entre otros, pero no evitaron una democratización social menos perceptible que ya había comenzado a transformar la política peruana en una espacio de participación popular.

\section{Referencias bibliográficas}

Acemoglu, D. y Robinson, J. A. (2006). Economic Origins of Dictatorship and Democracy. Cambridge: Cambridge University Press.

Arequipeño, A. y Jiménez, J. F. (1994). Las relaciones del Perú y Estados Unidos: ¿Hacia un nuevo enfoque?. Revista Pensamiento Constitucional, vol. 1, no. 1, pp. 93-124.

Basadre, J. (2005). Historia de la República del Perú 1822-1933, 18 tomos. Lima: Empresa Editora El Comercio S.A.

Bobbio, N. (2006a). La teoría de las formas de gobierno en la historia del pensamiento político. México: Fondo de Cultura Económica.

Bobbio, N. (2006b). Estado, gobierno y sociedad. Por una teoría general de la política. México: Fondo de Cultura Económica.

Chaney, E. (1988). El significado de la obra de María Jesús Alvarado. Lima: CEDOC Mujer.

Contreras, C. (1994). Sobre los orígenes de la explosión demográfica en el Perú: 1876-1940. Documento de trabajo no. 61, Serie Economía no. 21. Lima: Instituto de Estudios Peruanos.

Contreras, C. (2004). ¿Inmigración o autogenia? La política de población en el Perú, 18761940. En: El aprendizaje del capitalismo. Estudios de historia económica y social del Perú republicano (pp. 173-213). Lima: Instituto de Estudios Peruanos.

Delhom, J. (2001). El movimiento obrero anarquista en el Perú (1890-1930). Ponencia presentada en la Conferencia Anual de la Society for Latin American Studies de la 
Universidad de Birmingham, 6 al 8 de abril. Recuperado 1.03.2019 de http://dwardmac. pitzer.edu/Anarchist_Archives/worldwidemovements/peru/Movimiento.html

Francke, M. (1990). Género, clase y etnia: la trenza de la dominación. En C. I. Degregori et al., Tiempos de ira y amor (pp. 77-106). Lima: DESCO.

Garland, A. (1905). Reseña Industrial del Perú 1905. Lima: Ministerio de Fomento, Imprenta La Industria. Recuperado de https://archive.org/details/reseaindustrial00fomegoog

Held, D. (2007). Modelos de democracia. Madrid: Alianza Editorial.

Hunt, S. (1980). Evolución de los salarios reales en Perú 1900-1940, Economía, vol. 3 no. 5, pp. $83-123$.

Laclau, E. (2005). La razón populista. México: Fondo de Cultura Económica.

Lipset, S. M. (1996). Repensando los requisitos sociales de la democracia, Ágora, no. 5, pp. 29-65.

Macpherson, C. B. (2009). La democracia liberal y su época. Madrid: Alianza Editorial.

Martín, J. C. (1996). Instrucción pública (1904-1908). Boletín del Instituto Riva-Agüero, no. 23, pp. 413-426.

Marshall, T. H. (1997). Ciudadanía y clase social. Revista Española de Investigaciones Sociológicas, no. 79, pp. 297-346.

Massey, D. (2005). Filosofía y política de la espacialidad: Algunas consideraciones. En L. Arfuch (Comp.), Pensar este tiempo. Espacio, afectos, pertenencias. Buenos Aires: Paidós.

McEvoy, C. (1997). La utopía republicana. Lima: Fondo Editorial de la Pontificia Universidad Católica del Perú.

McEvoy, C. (1999). Forjando la nación. Ensayos de historia republicana. Lima: Instituto Riva-Agüero, Pontificia Universidad Católica del Perú.

Pérez, J. S. (2012). Historia del feminismo. Madrid: Catarata.

Rueschemeyer, D., Stephens, E. H., Stephens, J. D. (1992). Capitalist Development and Democracy. Chicago: University of Chicago Press.

Sanborn, C. (2004). Los obreros textiles de Lima: redes sociales y organización laboral, 1900-1930. En A. Panfichi, F. Portocarrero (Eds.), Mundos interiores: Lima 1850-1950 (pp. 187-215). Lima: Universidad del Pacífico.

Thorp R. y Bertram, G. (1985). Perú: 1890-1977. Crecimiento y políticas en una economía abierta. Lima: Mosca Azul Editores, Fundación Friedrich Ebert, Universidad del Pacífico.

Zegarra, M. D. (2011). María Jesús Alvarado: la construcción de una intelectual feminista en Lima, 1878-1915. Tesis de posgrado. Lima: Universidad Nacional Mayor de San Marcos.
Alcances y desarrollo del movimiento feminista y el movimiento obrero en la conformación de una democracia social en el Perú oligárquico, 1887-1919

Juan Francisco Morales Giraldo 